\title{
Controlled trial of biofeedback-aided behavioural methods in reducing mild hypertension
}

\author{
CHANDRA PATEL, M G MARMOT, D J TERRY
}

\begin{abstract}
Employees of a large industry were screened for the presence of coronary risk factors. A total of 204 employees, aged 35-64 years, with two or more such factors (serum cholesterol concentration $\geqslant 6.3 \mathrm{mmol} / 1$ $(243.6 \mathrm{mg} / 100 \mathrm{ml})$, blood pressure $\geqslant 140 / 90 \mathrm{~mm} \mathrm{Hg}$, and current cigarette consumption $\geqslant 10$ cigarettes a day) were randomly allocated to a biofeedback group receiving training in relaxation and management of stress or a control group. Both groups received simple health education literature. After eight weeks of training, and again eight months later, the biofeedback group showed a significantly greater fall in systolic and diastolic blood pressures than the control group $(p<0.001)$. Plasma renin activity and plasma aldosterone concentration were measured in a subsample at entry to the study and again at eight weeks and eight months; both showed a greater reduction in the biofeedback compared with the control group at eight weeks' follow-up.

The greater reduction in blood pressure in the subjects in the biofeedback group compared with the control group (11.0 mm $\mathrm{Hg}$ systolic and $8.8 \mathrm{~mm} \mathrm{Hg}$ diastolic), persisting eight months after the training, suggests that relaxation-based behavioural methods might be offered as a first-line treatment to patients with mild hypertension.
\end{abstract}

\section{Introduction}

Mild hypertension poses a dilemma for both the clinician and those concerned with health policy. Recent trials have shown

\footnotetext{
Department of Medical Statistics and Epidemiology, London School of Hygiene and Tropical Medicine, London WC1E 7HT CHANDRA PATEL, MD, MRCGP, general practitioner M G MARMOT, MB, PHD, senior lecturer in epidemiology

Philips Industries, Croydon, Surrey

D J TERRY, MB, MFOM, regional medical adviser
}

that reducing the blood pressure of patients with diastolic blood pressures as low as $90 \mathrm{~mm} \mathrm{Hg}$ reduces their risk of 0 coronary heart disease. ${ }^{12}$ Yet there is concern over the costs and hazards of putting a large proportion of the adult population on long-term antihypertensive drugs. Because of this non- $\vec{t}$ pharmacological approaches to the control of hypertension are increasingly being considered. ${ }^{3}{ }^{4}$

Several studies have shown that, in specially selected groups, relaxation techniques may be used to decrease antihypertensive medication and lower blood pressure..$^{5-19}$ We wished to determine whether one such technique of relaxation could be taught in a cost-effective manner to large unselected groups of men and women found at screening to have an increased risk of coronary heart disease but not receiving pharmacological treatment. We therefore conducted a randomised controlled trial of behaviour modification using biofeedback-aided relaxation. The subjects for this study had two or three of blood pressure $\geqslant 140 / 90 \mathrm{~mm} \mathrm{Hg}$, cholesterol concentration $\geqslant$ $6.3 \mathrm{mmol} / 1(243.6 \mathrm{mg} / 100 \mathrm{ml})$, and cigarette consumption $\geqslant 10 /$ day. We report the changes in blood pressure and plasma renin activity and aldosterone concentrations after eight weeks of "training" sessions and after eight months of follow-up.

\section{Subjects and methods}

All the employees aged between 35 and 64 years of a large manufacturing firm were invited for a screening examination. Of the 1268 invited, $1132(89 \%)$ attended. On the basis of a questionnaire and examination subjects with two or more risk factors were recalled for further assessment. The risk factors were defined as: an average of two blood pressure measurements of $140 / 90 \mathrm{~mm} \mathrm{Hg}$ or more in subjects not taking antihypertensive drugs; non-fasting serum cholesterol concentration of $6.3 \mathrm{mmol} / 1(243.6 \mathrm{mg} / 100 \mathrm{ml})$ or more; and current cigarette consumption of 10 cigarettes or more a day. Blood pressures were measured by a trained nurse using a random zero sphygmomanometer after the subjects had been sitting quietly for five minutes. Diastolic pressure was measured at phase 5 (disappearance of the Korotkoff sounds).

Of the 312 subjects invited for re-examination, 289 (93\%) attended. Each subject completed three self-administered 24-hour dietary recall diaries. At this stage 59 subjects were excluded because they no longer had two or more risk factors-that is, either the average of two further blood pressure measurements had fallen below 140/90 
$\mathrm{mm} \mathrm{Hg}$ or the person was smoking fewer than 10 cigarettes a day. Of the remaining 230 subjects, $204(89 \%)$ agreed to participate in the study. An electrocardiogram was recorded, and in a subsample a further specimen of blood was withdrawn by venepuncture for estimation of plasma renin activity and plasma aldosterone concentration. The subjects sat quietly for at least 10 minutes before the specimen was taken. The specimen was immediately centrifuged and the plasma separated and frozen on dry ice and later analysed blind using radioimmunoassay methods. Subjects were then randomly allocated to treatment (biofeedback) and control groups.

For both groups the management protocol consisted of 10 minutes of individual explanation about coronary risk factors and the plan of the study, and distribution of health education literature on modification of dietary fats and smoking. In addition the treatment group followed a behavioural modification programme consisting of one-hour group sessions once a week for eight weeks and a "stress" education programme as set out below.

During the session the subjects attended in groups of six to eight.

TABLE I-Comparison between biofeedback and control groups at entry to study

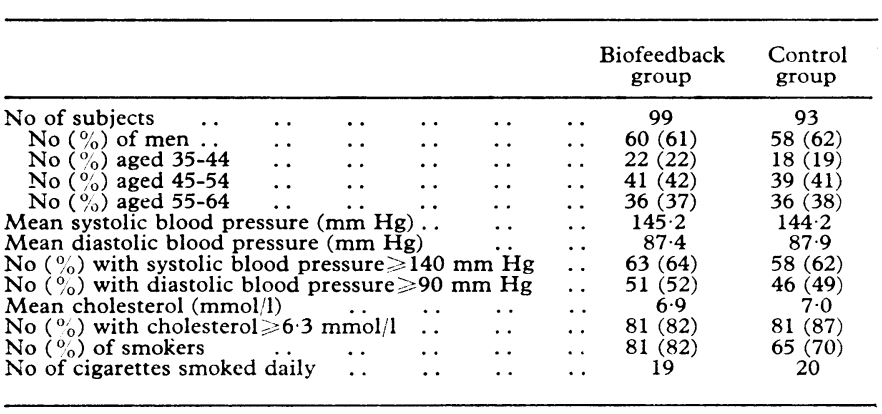

Conversion: SI to traditional units-Cholesterol: $1 \mathrm{mmol} / 1 \approx 38.7 \mathrm{mg} / 100 \mathrm{ml}$.
Training was given in breathing exercises, deep-muscle relaxation, and meditation, the instructions being given by means of a cassette tape. The relaxation was enhanced by means of a multicircuit galvanic skin resistance feedback machine developed for group use. The stress education programme consisted of audiovisual descriptions of the effect of psychosocial stimulation on blood pressure and coronary heart disease (including a film "Stresses and Strains" by Walt Disney Ltd); the rationale of relaxation; the what, why, and how of meditation; and integrating relaxation into everyday life. The subjects were requested to practise relaxation twice daily and were lent the relaxation and meditation instruction cassette tape for home practice.

Further assessments were made at the end of eight weeks and eight months. Subjects were not seen between the eight-week and eight-month follow-ups. Four measurements of blood pressure were made on two separate days during each follow-up. The procedure for blood sampling was the same as before. The subjects again filled in three 24-hour dietary recall diaries before each follow up examination. A further electrocardiogram was taken at eight weeks. Results of changes in cholesterol concentrations and smoking will be reported elsewhere.

\section{Results}

Of the 107 subjects allocated to the biofeedback group, 99 completed eight weeks of follow-up. Of the 97 allocated to the control group, 93 completed eight weeks. The characteristics of the 12 people who dropped out after randomisation were similar to those of the 192 who were followed up for eight weeks. Table I shows that the biofeedback and control groups were similar at entry to the study with respect to age, sex, number of subjects with raised blood pressure, and mean blood pressure. They were also similar with respect to plasma cholesterol concentration and number of cigarettes smoked daily. The proportion of current smokers was slightly higher in the treatment group.

Figures 1 and 2 show respectively the changes in systolic and

TABLE II-Mean $\pm S E$ reduction in blood pressure $(\mathrm{mm} \mathrm{Hg})$ in biofeedback and control groups at 8 weeks and 8 months $\dagger$

\begin{tabular}{|c|c|c|c|c|c|c|}
\hline & \multicolumn{2}{|c|}{ Biofeedback group } & \multicolumn{2}{|c|}{ Control group } & \multicolumn{2}{|c|}{$\begin{array}{c}\text { Between group difference } \\
(t \text { value })\end{array}$} \\
\hline & Systolic & Diastolic & Systolic & Diastolic & Systolic & Diastolic \\
\hline \multicolumn{7}{|c|}{ All subjects } \\
\hline Reduction at 8 weeks .. & $\begin{array}{c}13 \cdot 8 \pm 1 \cdot 34 \\
(\mathrm{n}=99)\end{array}$ & $\begin{array}{l}7 \cdot 2 \pm 0.91 \\
(\mathrm{n}=99)\end{array}$ & $\begin{array}{l}4 \cdot 0 \pm 1 \cdot 30 \\
(n=93)\end{array}$ & $\begin{array}{l}1 \cdot 4 \pm 0 \cdot 81 \\
(\mathrm{n}=93)\end{array}$ & $5 \cdot 29 * * *$ & $4 \cdot 75^{* * *}$ \\
\hline Reduction at 8 months & $\begin{array}{c}15 \cdot 3 \pm 1 \cdot 55 \\
(\mathrm{n}=95)\end{array}$ & $\begin{array}{l}6 \cdot 8 \pm 0.95 \\
(\mathrm{n}=95)\end{array}$ & $\begin{array}{c}6 \cdot 1 \pm 1 \cdot 56 \\
(\mathrm{n}=84)\end{array}$ & $\begin{array}{c}0.63 \pm 0.91 \\
(\mathrm{n}=84)\end{array}$ & $4 \cdot 18^{* * *}$ & $4 \cdot 69^{* * *}$ \\
\hline \multicolumn{7}{|c|}{ Subjects with blood pressure $\geqslant 140 / 90 \mathrm{~mm} \mathrm{Hg}$} \\
\hline Reduction at 8 weeks .. & $\begin{array}{c}19 \cdot 6 \pm 2 \cdot 06 \\
(\mathrm{n}=50)\end{array}$ & $\begin{array}{c}10 \cdot 6 \pm 1 \cdot 40 \\
(\mathrm{n}=50)\end{array}$ & $\begin{array}{c}8 \cdot 2 \pm 1 \cdot 64 \\
(n=43)\end{array}$ & $\begin{array}{l}3 \cdot 6 \pm 1 \cdot 10 \\
(n=43)\end{array}$ & $4 \cdot 24^{* * *}$ & $3 \cdot 85^{* * *}$ \\
\hline Reduction at 8 months.. & $\begin{array}{c}22 \cdot 4 \pm 2 \cdot 39 \\
(\mathrm{n}=48)\end{array}$ & $\begin{array}{c}11 \cdot 5 \pm 1 \cdot 34 \\
(\mathrm{n}=48)\end{array}$ & $\begin{aligned} 11 \cdot 4 & \pm 1 \cdot 87 \\
(\mathrm{n} & =40)\end{aligned}$ & $\begin{aligned} 2 \cdot 7 & \pm 1 \cdot 32 \\
(\mathrm{n} & =40)\end{aligned}$ & $3 \cdot 52 * * *$ & $4 \cdot 64^{* * *}$ \\
\hline
\end{tabular}

Significance: ${ }^{* * *} \mathrm{p}<0.001$.

+Values were not determined in four subjects in the biofeedback group and nine in the control group at 8 months.

TABLE III-Changes in log plasma renin activity and plasma aldosterone concentration in biofeedback and control groups at 8 weeks and 8 months

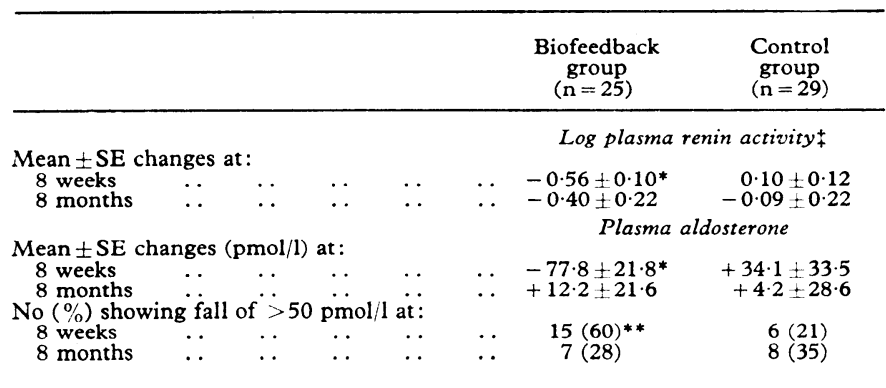

tThe following measurements were unsuccessful: plasma renin activity in two controls at eight weeks and in two subjects in the biofeedback group and six controls group and six controls at eight months.

†Plasma renin activity = generation of angiotensin $I$ in plasma $/ \mathrm{hour}(\mathrm{pg} / \mathrm{ml} / \mathrm{h})$. Significance of difference between biofeedback and control groups: ${ }^{*} 0.01<\mathrm{p}<0.05$;

**0.001 $<\mathrm{p}<0.01$ (two tailed).
Conversion: SI to traditional units-Plasma aldosterone: $1 \mathrm{pmol} / 1 \approx 36 \mathrm{pg} / 100 \mathrm{ml}$. diastolic blood pressures in all the subjects and the changes in the subgroup with baseline blood pressures of $140 / 90 \mathrm{~mm} \mathrm{Hg}$ or more. Table II shows the reductions in blood pressure. The drop in both systolic and diastolic pressures was greater in the biofeedback group than the control group, at eight weeks as well as at eight months, both in all the subjects studied and in the subgroup with blood pressure $\geqslant 140 / 90 \mathrm{~mm} \mathrm{Hg}$. Plasma renin activity and plasma aldosterone concentrations were measured in a subsample of 54 subjects. There was a significantly greater reduction in both plasma renin activity and plasma aldosterone concentration in the biofeedback as compared with the control group at eight weeks but not at eight months (table III). There was no correlation between the changes in blood pressure and in plasma renin activity in either group, but there were significant correlations between changes in aldosterone concentration and in both systolic and diastolic blood pressures at eight weeks (table IV).

The heart rate, as determined by electrocardiography, was reduced by an average of 4.5 beats $/ \mathrm{min}$ in the biofeedback group (significance of within-group difference $\mathrm{p}=0.001$ ), and 1.2 beats $/ \mathrm{min}$ in the control group. The difference between the groups, although in the predicted direction, was not significant $(\mathrm{p}<0.08)$. 
TABLE IV-Correlation between changes in blood pressure and in aldosterone concentration and plasma renin activity

\begin{tabular}{llcccc}
\hline & \multicolumn{2}{c}{ Biofeedback group } & \multicolumn{2}{c}{ Control group } \\
\cline { 2 - 6 } \multicolumn{1}{c}{$\begin{array}{c}\text { Correlation coefficient } \\
\text { between changes in: }\end{array}$} & $\begin{array}{c}8 \text { weeks } \\
(\mathrm{n}=25)\end{array}$ & $\begin{array}{c}8 \text { months } \\
(\mathrm{n}=23)\end{array}$ & $\begin{array}{l}8 \text { weeks } \\
(\mathrm{n}=25)\end{array}$ & $\begin{array}{c}8 \text { months } \\
(\mathrm{n}=23)\end{array}$ \\
\hline $\begin{array}{l}\text { Systolic blood pressure and } \\
\text { aldosterone }\end{array}$ & $0.542^{* *}$ & 0.177 & 0.015 & 0.150 \\
$\begin{array}{l}\text { Diastolic blood pressure and } \\
\text { aldosterone }\end{array}$ & $0.475^{*}$ & 0.303 & 0.118 & 0.197 \\
$\begin{array}{l}\text { Systolic blood pressure and log } \\
\text { plasma renin activity }\end{array}$ & 0.015 & 0.230 & 0.029 & 0.166 \\
$\begin{array}{l}\text { Diastolic blood pressure and log } \\
\text { plasma renin activity }\end{array}$ & 0.062 & -0.134 & 0.153 & -0.280 \\
$\begin{array}{l}\text { Log plasma renin activity and } \\
\text { aldosterone }\end{array}$ & $0.398^{*}$ & 0.226 & 0.122 & 0.257 \\
\hline
\end{tabular}

Significance of difference from control group: ${ }^{*} 0.01<\mathrm{p}<0.05 ;{ }^{* *} 0.001<\mathrm{p}<0.01$

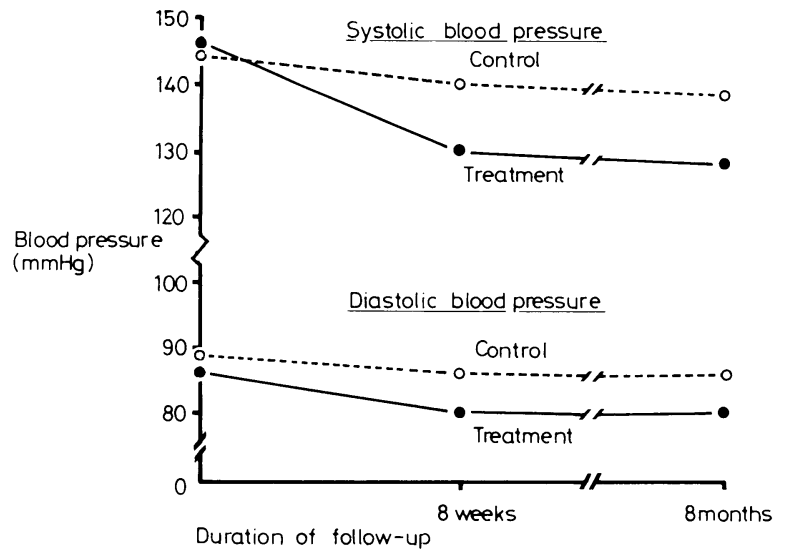

FIG 1-Changes in systolic and diastolic blood pressure after eight weeks and eight months in all subjects studied.

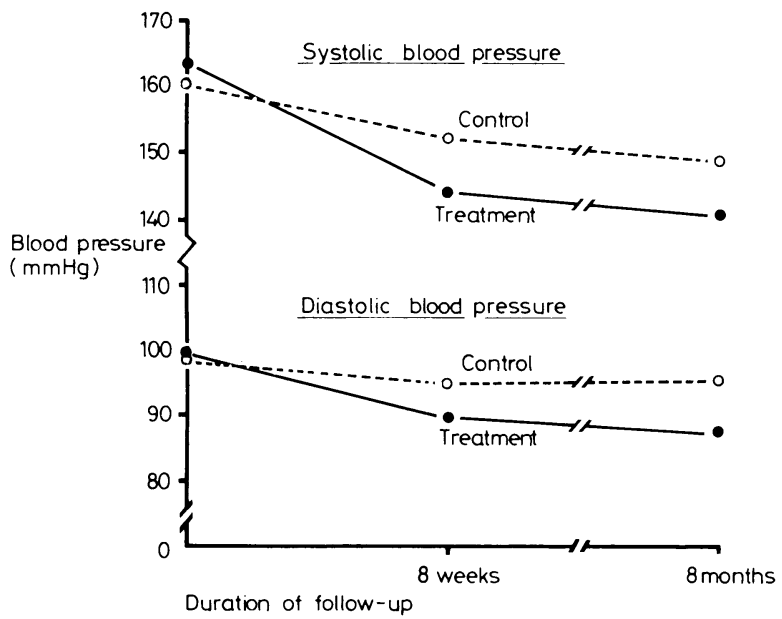

FIG 2-Changes in systolic and diastolic blood pressures at eight weeks and eight months in high-risk group with blood pressure $\geqslant 140 / 90 \mathrm{~mm} \mathrm{Hg}$.

Both groups received health education, which included for ethical reasons advice about the possible hazards of a high-fat diet. The greater reductions observed in blood pressure in the biofeedback group might possibly have been the result of changes in diet. As assessed by dietary diaries covering three days the average dietary intakes of the two groups were similar at entry to the study. There was some evidence of a reduction in the intake of total energy, total fat, and animal fat in both groups but little difference between the groups in the amount of change.

Weight was measured at entry and at each of the follow up examinations. Despite the reported dietary changes, weight did not change in either group. This was further evidence that the blood pressure differences between the biofeedback and control groups were unrelated to dietary or weight changes.

\section{Discussion}

Since it was impractical to perform the study blind attempts were made to standardise the measurements as closely as possible. All blood pressure measurements, with the exception of those in the first 25 subjects in each group, were made by the same nurse, and all observers underwent special training in blood pressure measurement ${ }^{20}$ and used a random zero sphygomomanometer. This did not eliminate the possibility of systematic bias in recording but did reduce it.

The measurements of plasma renin activity and aldosterone concentration are unlikely to have been biased. Hence the greater decrease in the biofeedback group-significant at eight weeks-was probably due to some long-term biochemica! changes. We do not believe that the observed blood pressure changes were due merely to the subjects learning how to reduce their blood pressure while it was being measured. The changes in blood pressure in the control group underlined the crucial importance of having a control group in a study of this nature and not relying on before and after comparisons.

The greater contact of the biofeedback group with medical staff may possibly, in some non-specific way, have resulted in decreases in blood pressure through relaxation. We do not think that this the most likely explanation. In a previous controlled study Patel and North brought the control subjects into the clinic as many times as the biofeedback subjects and still found a significantly greater decrease in blood pressure in the biofeedback group. ${ }^{6}$ ?

A significant decrease in plasma renin activity and plasma aldosterone concentrations had occurred at eight weeks, with a positive correlation between changes in blood pressure and in aldosterone concentration but not between changes in blood pressure and in plasma renin activity. The mechanisms of blood pressure reduction, however, are complex and not completely clear. The sympathetic nervous system is one of the controlling factors of the renin-angiotensin-aldosterone system. ${ }^{21}$ The reductions occurred after eight weeks during which the subjects were practising relaxation intensively and regularly, but the values reverted back to their original level after eight months, when most of the subjects would be expected to practise relaxation on only a limited basis. This suggests that the mechanisms responsible for long-term maintenance of blood pressure reduction might differ from those responsible for acute reduction. In many hypertensive patients control of blood pressure becomes easier with time and if antihypertensive drugs are stopped the blood pressure may not start to rise for several weeks. A partial reversal of some of the factors responsible for maintaining and perpetuating hypertension and the prolongation of this by limited practice of regular relaxation may play a part in long-term reduction as shown in animal and human experiments. ${ }^{22} 23$

We thank Professor Geoffrey Rose for his advice; Mrs B Hunt for statistical help; and Mrs M Marshall, Mrs E Carrington, Mrs $M$ Footer, Mrs M Wyatt, Mrs A Johnson, Miss F Pike, and Miss P Botley for their help. We also thank Philips Industries for allowing us to conduct this study. This study was supported by the British Heart Foundation and the South-west Thames Regional Health Authority. Dr Marmot is supported in part by the British Heart Foundation. We thank Professor P Sever and Professor V H T James (St Mary's Hospital, London) for estimating plasma renin activity and plasma aldosterone concentrations respectively.

\section{References}

${ }^{1}$ Hypertension Detection and Follow-up Program Co-operative Group. Five-year findings of the hypertension detection and follow-up program. I. $\mathcal{F} A M A 1979 ; \mathbf{2 4 2}: 2562-70$. 
${ }^{2}$ Management Committee. The Australian therapeutic trial in mild hypertension. Lancet $1980 ; \mathrm{i}: 1261-7$.

${ }^{3}$ Stamler J, Farinaro E, Mojonnier LM, Hall Y, Moss D, Stamler R. Prevention and control of hypertension by nutritional-hygienic means. F $A M A$ 1980;243:1819-23.

4 Anonymous. Lowering blood pressure without drugs. Lancet 1980;ii: 459-61.

5 Patel C. Yoga and biofeedback in the management of hypertension. Lancet 1973;ii:1053-5.

6 Patel C. 12-month follow-up of yoga and biofeedback in the management of hypertension. Lancet $1975 ; \mathrm{i}: 62-4$.

${ }^{7}$ Patel C, North WR. Randomized controlled trial of yoga and biofeedback in the management of hypertension. Lancet 1975;ii:93-5.

${ }^{8}$ Datey K, Deshmukh SN, Dalvi CP, Vinekar MD. "Shavasan"; a yogic exercise in the management of hypertension. Angiology $1969 ; 20: 325-33$.

9 Benson H, Shapiro D, Tursky B, Schwartz G. Decreased systolic blood pressure through operant conditioning techniques in patients with essential hypertension. Science $1971 ; 173: 740-2$.

10 Elder ST, Ruiz ZR, Deabler HL, Dillenkoffer RL. Instrumental conditioning of diastolic blood pressure in essential hypertensive patients. f Appl Behav Anal 1973;6:377-82.

${ }^{11}$ Kristt DA, Engel BT. Learned control of blood pressure in patients with high blood pressure. Circulation $1975 ; \mathbf{5 1}: 370-8$.

: Benson HB, Rosner BA, Marzetta BR, Klemchuk HM. Decreased blood pressure in pharmacologically treated hypertensive patients who regularly elicited the relaxation response. Lancet $1974 ; \mathrm{i}: 289-91$.

${ }^{13}$ Shoemaker JE, Tasto DL. The effects of muscle relaxation on blood pressure in essential hypertensives. Behav Res Ther 1975;13:29-43.

14 Blackwell BS, Bloomfield P, Grantside P, et al. Transcendental meditation in hypertension. Lancet $1976 ; \mathrm{i}: 223-6$.
15 Stone A, De Leo J. Psychotherapeutic control of hypertension. $N$ Engl $\mathcal{F}$ Med 1976;294:80-4.

${ }^{16}$ Deabbler HL, Fedel E, Dillenkoffer RL. The use of relaxation and hypnosis in lowering high blood pressure. Am f Clin Hypn 1973;16: 75-83.

17 Taylor CB, Farquar JW, Nelson E, Agros S. Relaxation therapy and $\varrho$ high blood pressure. Arch Gen Psychiatry 1977;34:339-42.

18 Peters RK, Benson H, Peters JM. Daily relaxation response breaks in a $\widehat{\Omega}$ working population. II. Effects on blood pressure. Am $\mathcal{f}$ Public Health 1977;67:954-9.

19 Luborsky L, Crits-Christoph P, Brady JP, Kron RE, Weiss T, Engelman $\mathrm{K}$. Antihypertensive effects of behavioral treatments and $\infty$ medications compared. $N$ Engl f Med 1980;303:586.

${ }^{20}$ Rose GA. Standardisation of observers in blood pressure measurement. Lancet $1965 ; \mathrm{i}: 673-4$.

${ }^{21}$ Oparil S, Katholi R. Renin release-autonomic mechanisms. In: Oparil S, Katholi R, eds. Renin. Vol 3. Edinburgh: Churchill Livingstone, 1978: 음 35-73.

${ }^{22}$ Folkow B, Hallback M. Lundgren Y, Sivertsson R, Weiss L. Importance $\overline{\bar{\omega}}$ of adaptive changes in vascular design for establishment of primary $\vec{\partial}$ hypertension, studied in man and in spontaneously hypertensive rats. Circ Res 1973;32, suppl 1:2-16.

${ }^{23}$ Vaughan Williams EM, Hassan MO, Floras JS, Sleight P, Jones VJ. ๗ँ Adaptation of hypertensives to treatment with cardio selective and $\vec{O}$ non-selective beta-blockers. Absence of correlation between bradycardia and blood pressure control and reduction in slope of QT/RR relation. Br Heart $\mathcal{F} 1980 ; 44: 437-97$.

(Accepted 22 April 1981)

\title{
Aquagenic pruritus
}

\author{
M W GREAVES, A K BLACK, R A J EADY, A COUTTS
}

\begin{abstract}
Three patients were studied in whom brief contact of the skin with water at any temperature evoked intense itching without visible changes in the skin. The patients were otherwise apparently healthy, and this chronic and disabling disorder tended to attract a "psychogenic" label. Pharmacological studies showed that the condition was associated with local release of acetyl choline in the skin, mast-cell degranulation, and raised blood histamine concentrations. It responded well to antihistamines in two of the three patients.

Aquagenic pruritus is probably common, but it is generally unrecognised and may be misdiagnosed. Antihistamines may induce a good therapeutic response.
\end{abstract}

\section{Introduction}

Transitory contact of the skin with water is generally thought to be completely innocuous. This report describes a novel and disabling reaction of the skin to water with mast-cell degranulation and increased circulating histamine activity. Its recognition

Institute of Dermatology, St John's Hospital for Diseases of the Skin, London E9

$M$ W GREAVES, MD, FRCP, professor of dermatology

A K BLACK, MRCP, senior lecturer and consultant

R A J EADY, MRCP, senior lecturer and consultant

A COUTTS, PHD, lecturer is important because sufferers are liable to be labelled "neurotic" and because it responds well to antihistamines. It also appears to be a common disorder.

\section{Case reports}

CASE 1

A 24-year-old Ghanaian catering student who had been living in Britain for nine years complained of intense extensive pruritus after contact of her skin with water at any temperature. The complaint 0 had been present persistently for 14 years and there were no visible 3 . skin changes. Typically, the irritation developed on the legs within a few minutes of immersion in a hot or cold bath, became generalised, $\frac{0}{3}$ and lasted 15-45 minutes. It was associated with dizziness and palpitations. Of the several doctors who had seen her previously, one had considered that she had "a number of personality problems" and N another that she had a "psychogenic problem." Exposure to cold, heat, exercise, and emotional stimuli produced no effects. General medical o history and examination contributed nothing. The skin looked normal and she was not dermographic. Exercise on a stationary $N$ bicycle failed to reproduce the symptoms. Laboratory tests including $\underset{\omega}{N}$ full blood variables, thyroid function, liver and renal function, serum $O$ IgE concentration, and serum complement components were all within normal limits.

She was immersed in water at $37^{\circ} \mathrm{C}$ for 15 minutes up to her upper $\mathbb{\infty}$ chest. After four minutes she developed intense itching in the front : and back of the legs. After 15 minutes this had spread to the back, but $\frac{0}{0}$ at 35 minutes it had diminished considerably. There were no visible $\vec{P}$ skin changes. She had no systemic symptoms on this occasion, and peak expiratory flow rate measured by Wright's peak flow meter was $\stackrel{\mathbb{Q}}{\Omega}$ $440 \mathrm{l} / \mathrm{min}$ before immersion and varied from 430 to $460 \mathrm{l} / \mathrm{min}$ after $O$ immersion. An area of skin in which sweating had been blocked by earlier topical application of $3 \%$ hyoscine solution failed to itch, although surrounding skin itched. Cimetidine $200 \mathrm{mg}$ and chlorpheniramine $8 \mathrm{mg}$ were both given six hourly for 24 hours. Immersion in 을 